\title{
Dabigatran and other oral antithrombotic agents for the prevention of stroke in patients with atrial fibrillation
}

This article was published in the following Dove Press journal:

Research Reports in Clinical Cardiology

22 June 2011

Number of times this article has been viewed

\section{Fernando D Testai \\ Venkatesh Aiyagari}

Section of Neurological Critical Care and Stroke, Department of Neurology and Rehabilitation, Center for Stroke Research, University of Illinois College of Medicine, Chicago, IL, USA
Correspondence: Fernando D Testai Section of Neurological Critical Care and Stroke, Department of Neurology and Rehabilitation, Center for Stroke Research, University of Illinois College of Medicine, 912 S. Wood Street, Room $855 \mathrm{~N}$, Chicago, IL 606 I2, USA

$\mathrm{Tel}+\mathrm{I} 3129961047$

Fax + I 312 413 8215

Email testai@uic.edu

\begin{abstract}
Atrial fibrillation (AF) is considered to be one of the most prevalent abnormal heart rhythm disorders and a leading cause of cerebral ischemia. The risk of stroke in AF is associated with vascular risk factors including advancing age, hypertension, congestive heart disease, diabetes mellitus, vascular disease, and prior history of stroke or transient ischemic attack. The classic management of patients with AF at risk of suffering stroke includes the use of warfarin. The use of this medication in clinical practice is, however, limited owing to its narrow therapeutic window, multiple drug and food interactions, prolonged half-life, and the need for periodic anticoagulation monitoring. Recently, newer oral anticoagulants with better pharmacokinetic and pharmacodynamic profiles have been developed and compared to warfarin in phase III trials for the prevention of stroke and systemic embolism in patients with AF. Dabigatran stands out from these studies as a safe and efficacious alternative to warfarin for treating patients with AF at risk of stroke. In this article we review classic and novel approaches for stroke prevention in AF with special emphasis on dabigatran.
\end{abstract}

Keywords: oral anticoagulants, vitamin K antagonists, antiplatelet agents, stroke prevention, atrial fibrillation

\section{Introduction}

Atrial fibrillation (AF) is the most common arrhythmia seen in clinical practice. In the United States, the age adjusted prevalence of AF was estimated at $2.5 \%$ in 2000 , with a higher incidence in males and African Americans. ${ }^{1}$ The prevalence of AF also increases with age and is estimated at $6.0 \%$ among Medicare patients $\geq 65$ years of age and $18.2 \%$ among subjects $\geq 85$ years of age. ${ }^{1,2}$ Population based studies have shown an increase in the prevalence of $\mathrm{AF}$ over time and it has been estimated that by the year 2050, over 12 million adults in the United States will have this condition. ${ }^{1}$ During the past 20 years, hospital admissions for AF have increased by $66 \%$. Finally, AF is an expensive disease with costs approaching US $\$ 3,600$ per patient per year. Thus AF has been rightly termed the "epidemic of the new millennium". ${ }^{3}$

AF primarily leads to two consequences: a) myocardial and hemodynamic effects of the rhythm disorder, leading to a decrease in cardiac output, and b) thromboembolism from left atrial clots formed due to stasis, leading to stroke and systemic arterial embolism. These are manifested in the form of an increased risk of stroke by two- to seven-fold, a doubling of the risk of dementia, a tripling of the risk of heart failure, and a doubling of all-cause mortality. 4,5 Management of patients with AF involves control of the heart rate or correction of heart rhythm and prevention of thromboembolism. Anticoagulation with vitamin $\mathrm{K}$ antagonists has been shown to be very effective in 
decreasing the incidence of thromboembolic complications, albeit at the cost of an increase in hemorrhagic complications. This has led to an increasing interest in developing alternative strategies to prevent thromboembolism, including newer anticoagulants such as factor Xa inhibitors and direct thrombin inhibitors (DTI).

In this manuscript, we review the association of stroke with $\mathrm{AF}$ and the role of vitamin $\mathrm{K}$ antagonists (warfarin), antiplatelet agents, and newer oral anticoagulants, particularly dabigatran, in stroke prevention in AF.

\section{Stroke risk in AF}

AF is responsible for about $10 \%$ of all ischemic strokes in the United States. ${ }^{6}$ However, this risk is not homogenous and is influenced by several factors such as age, sex, hypertension, diabetes, and heart failure. These risk factors have been used to develop several thromboembolic risk stratification schemes. The most commonly used in clinical practice is the $\mathrm{CHADS}_{2}$ (cardiac failure, hypertension, age, diabetes, stroke) score where one point is assigned for age $>75$ years, a history of hypertension, diabetes, or heart failure and two points are assigned for a history of stroke or transient ischemic attack. ${ }^{7}$ A score of zero points indicates low risk $(0.5 \%-1.7 \%$ year), one point moderate risk $(1.2 \%-2.2 \%$ per year), and two or more points high risk $(1.9 \%-7.6 \%$ per year) of thromboembolism. ${ }^{8}$ There are several limitations of the existing risk stratification schemes and their external validity has been questioned. ${ }^{9}$ The $\mathrm{CHA}_{2} \mathrm{DS}_{2}$-VASc (congestive heart failure/ left ventricular dysfunction, hypertension, age $\geq 75$ years, diabetes mellitus, stroke, vascular disease, age 65-74 years, sex category) has been developed to overcome some of these limitations. ${ }^{10}$ The postulated advantage of this risk stratification system is that it is able to identify truly "low risk" AF patients as those with a $\mathrm{CHA}_{2} \mathrm{DS}_{2}$-VASc score of zero who may not need any form of antithrombotic therapy, while all others can be considered for anticoagulation. The $\mathrm{CHA}_{2} \mathrm{DS}_{2}-$ VASc has been incorporated into the latest European Society of Cardiology guidelines. ${ }^{11}$

\section{Classic therapies}

Cardioversion and rhythm control do not significantly reduce the stroke risk in AF and, classically, reduction of stroke risk in AF has been achieved by the use of oral anticoagulants or antiplatelet agents. ${ }^{12}$

\section{Vitamin $\mathrm{K}$ antagonists}

Conclusive evidence from several large randomized clinical trials has demonstrated that vitamin $\mathrm{K}$ antagonists (eg, warfarin) are effective in primary and secondary prevention of strokes in AF. Treatment with warfarin, adjusted to achieve an international normalized ratio (INR) between 2.0 and 3.0, leads to a $64 \%$ relative risk (RR) reduction of stroke (95\% confidence interval [CI] 49\%-74\%) compared to control, with annual absolute risk reductions of $2.7 \%$ for primary prevention and $8.4 \%$ for secondary prevention. ${ }^{13}$ Compared to aspirin, warfarin leads to a RR reduction of stroke of 39\% (95\% CI 6\%-35\%). However, despite these impressive results, in the real world, only half of all high risk patients actually receive warfarin, mainly because of a fear of bleeding. ${ }^{14}$ In most of the major clinical trials, the risk of major bleeding on warfarin is around $2 \%$ per year. Advanced age, labile INR, and concomitant use of antiplatelet agents appear to be the most predictive of major bleeding on warfarin and several risk scoring systems have been developed to assess bleeding risk. ${ }^{15}$ Thus, while warfarin is undoubtedly effective in preventing strokes in AF, it is a challenging drug to use in clinical practice. Some of these challenges include a variable dose response, interactions with medications and diet, need for frequent monitoring of the INR, narrow therapeutic window, significant bleeding complications, and long half-life. Even in well conducted clinical trials, patients are in the therapeutic range only two-thirds of the time, and in clinical practice, the time in therapeutic range (TTR) is even less. This has spurred an interest in developing newer oral anticoagulants.

Recently, a new vitamin $\mathrm{K}$ antagonist, tecarfarin, that is not metabolized by the cytochrome p450 system and has fewer drug interactions than warfarin, has been developed. In a phase IIa trial, the mean time in a therapeutic INR range on tecarfarin was $71 \%$, compared to $59 \%$ on warfarin prior to enrollment. ${ }^{16}$

The American Heart Association/American Stroke Association recommends the use of adjusted dose warfarin (target INR 2.0 to 3.0) "for all patients with nonvalvular AF deemed to be at high risk and many deemed to be at moderate risk for stroke who can receive it safely (Class I; Level of Evidence A)". ${ }^{17}$ It is also recommended "for patients with ischemic stroke or transient ischemic attack with paroxysmal (intermittent) or persistent AF (Class I; Level of Evidence A)". ${ }^{18}$

\section{Single antiplatelet therapy}

Aspirin has a modest effect on stroke prevention in AF with a RR reduction of $22 \%$ (95\% CI $22 \%-52 \%) .{ }^{13}$ However, it is worth mentioning that the beneficial effect of aspirin is largely driven by a single trial (Stroke Prevention in AF - I) 
where the trial was stopped early and there was internal heterogeneity. In the Birmingham AF Treatment of the Aged Trial, warfarin was found to be superior to aspirin for stroke prevention. ${ }^{19}$ Doses ranging from $50 \mathrm{mg}$ to $325 \mathrm{mg}$ have been studied and seem to offer similar benefits. The American Heart Association/American Stroke Association recommends the use of aspirin alone "for low-risk and some moderate risk patients with $\mathrm{AF}$, based on patient preference, estimated bleeding risk if anticoagulated, and access to high-quality anticoagulation monitoring" and for "patients unable to take oral anticoagulants" (Class I; Level of Evidence A)". ${ }^{17,18}$ The European guidelines, however, prefer no antithrombotic treatment rather than aspirin in low-risk patients $\left(\mathrm{CHA}_{2} \mathrm{DS}_{2}-\right.$ VASc score of zero) and anticoagulation in patients at a higher risk $\left(\mathrm{CHA}_{2} \mathrm{DS}_{2}-\mathrm{VASc}\right.$ score of $\left.\geq 1\right)$. ${ }^{11}$

\section{Dual antiplatelet therapy}

The combination of clopidogrel (75 mg daily) and aspirin (75 mg to $100 \mathrm{mg}$ daily) in stroke prevention in AF patients with at least one additional stroke risk factor has been studied by the AF Clopidogrel Trial with Irbesartan for prevention of Vascular Events (ACTIVE) investigators. ACTIVE-W compared this regimen with adjusted-dose warfarin (target INR 2.0 to 3.0) and found a $44 \%$ RR increase (95\% CI 18\%-76\%) in primary outcome events (stroke, non-central nervous system [CNS] systemic embolus, myocardial infarction, or vascular death) compared to warfarin. For stroke alone, the RR increase was $72 \%$ (95\% CI 24\%-137\%). Rates of major hemorrhages were similar in both groups. ${ }^{20}$ ACTIVE-A compared dual antiplatelet regimen with aspirin alone in patients deemed unsuitable for warfarin. In the dual antiplatelet arm, there was a reduction in major vascular events (RR with clopidogrel $0.89,95 \%$ CI $0.81-0.98$ ), especially stroke (RR with clopidogrel $0.72,95 \%$ CI 0.62-0.83), but an increase in major bleeding (RR with clopidogrel 1.57, 95\% CI 1.29-1.92). ${ }^{21}$ For patients unable to take oral anticoagulants, the American Heart Association/ American Stroke Association primary stroke prevention guidelines consider dual antiplatelet therapy as "might be reasonable"; but the phrase "not recommended" is used in secondary stroke prevention guidelines. ${ }^{17,18}$

\section{Newer oral anticoagulants}

Newer oral anticoagulants are being developed to overcome several of the challenges posed by warfarin as discussed earlier. Several of these new drugs, including DTI and oral factor Xa inhibitors, are under assessment in phase III trials for the prevention of stroke and systemic embolism in patients with AF.

\section{DTI}

\section{Ximelagatran}

Ximelagatran was the first DTI to be evaluated in the management of AF. In the pooled analysis of two large randomized clinical trials comparing ximelagatran with warfarin, the rates of major clinical events (combined ischemic stroke, hemorrhagic stroke, and systemic embolism) were similar in both groups and bleeding complications were lower in the ximelagatran group. ${ }^{22}$ However, the hepatotoxicity associated with ximelagatran, including fatal liver injury, led the United States Food and Drug Administration to deny approval to ximelagatran for stroke prevention.

\section{Dabigatran}

\section{Pharmacology}

Dabigatran etexilate is a non-peptide prodrug that is rapidly absorbed in the stomach and in the intestine. After absorption, plasma and liver esterases release the active dabigatran moiety, a competitive and reversible inhibitor of free thrombin, clot-bound thrombin, and thrombin-induced platelet activation. ${ }^{23}$ The time to maximum plasma concentration $\left(\mathrm{t}_{\max }\right)$ is 1.5 hours, and the maximum effect is observed in 2 hours. ${ }^{24}$ The bioavailability is low $(3 \%-7 \%)$ but increases by $75 \%$ if the drug is administered orally without the capsule shell. ${ }^{25} \mathrm{~A}$ fat-rich meal may prolong the $t_{\max }$ by 2 hours but does not affect the steady state levels; thus food is not considered a clinically relevant variable. ${ }^{26}$ Due to its modest tissue distribution and low human plasma protein binding (35\%), dabigatran is dialyzable and has few displacement interactions. Approximately $86 \%$ of the oral dose is eliminated in feces and, after intravenous administration, $80 \%-85 \%$ of the systemically available drug is excreted intact in urine and $10 \%$ is metabolized to active acyl glucuronides. ${ }^{27}$ The mean terminal half-life $\left(t_{1 / 2}\right)$ is $12-14$ hours. The clearance of dabigatran is not significantly affected by moderate hepatic impairment (Child-Pugh score B), but the $\mathrm{t}_{1 / 2}$, area under the curve $(\mathrm{AUC})$ and maximum plasma concentration $\left(\mathrm{C}_{\max }\right)$ are prolonged in individuals with renal impairment (Table 1). ${ }^{28}$ Dabigatran is not an inducer, inhibitor, or substrate of cytochrome 450 isoenzymes; therefore, it does not interact with drugs that are metabolized by this system, such as digoxin, benzodiazepines, statins, or nonsteroidal anti-inflammatory drugs. ${ }^{29}$ Dabigatran, however, is a substrate of the efflux P-glycoprotein system, and significant interactions have been described with drugs that utilize this transporter. For example, the P-glycoprotein inducer rifampin at a dose of $600 \mathrm{mg}$ daily for 7 days decreases the AUC and the $\mathrm{C}_{\max }$ of dabigatran by approximately $66 \%$ and, thus, the concomitant 
Table I Effect of renal function on pharmacokinetic parameters of dabigatran after oral administration of $150 \mathrm{mg}$

\begin{tabular}{llll}
\hline $\begin{array}{l}\text { Group }(\mathrm{CrCl}, \\
\mathbf{m L} / \text { minute) }\end{array}$ & $\begin{array}{l}\text { Increase } \\
\text { in AUC }\end{array}$ & $\begin{array}{l}\text { Increase } \\
\text { in } \mathbf{C}_{\max }\end{array}$ & $\mathbf{t}_{1 / 2}(\mathbf{h})$ \\
\hline $\begin{array}{l}\text { Control } \\
\text { Mild renal impairment }\end{array}$ & $\begin{array}{l}\text { Reference } \\
(\leq 80 \text { to }>50)\end{array}$ & $\begin{array}{l}\text { Reference } \\
\text { I.IIx }\end{array}$ & 13.8 \\
$\begin{array}{l}\text { Moderate renal impairment } \\
(\leq 50 \text { to }>30)\end{array}$ & $3.1 \times$ & $1.70 x$ & 18.6 \\
Severe renal impairment $(\leq 30)$ & $6.3 x$ & $2.12 x$ & 27.5 \\
\hline
\end{tabular}

Abbreviations: $A \cup C$, area under the curve; $C_{\max }$, maximum plasma concentration; $\mathrm{CrCl}$, creatinine clearance; $\mathrm{t}_{1 / 2}$, mean terminal half-life.

Notes: Data obtained from Stangier et al. ${ }^{28}$

use of these two medications should be avoided. Conversely, P-glycoprotein inhibitors such as amiodarone $(600 \mathrm{mg})$ and immediate-release verapamil increase the AUC by $60 \%$ and $150 \%$, respectively. ${ }^{25}$ These interactions are not clinically relevant and do not require dose adjustment. However, the coadministration of dabigatran and other potent $\mathrm{P}$-glycoprotein inhibitors, such as ketoconazole, is contraindicated. ${ }^{30} \mathrm{In}$ in vitro tests, dabigatran is not carcinogenic or mutagenic; however, decreased implantation, increased number of dead offspring, and increased incidence of fetal skeletal variations were observed in animal models..$^{31}$ The effect of dabigatran in pregnant or lactating women has not been investigated. The potency of dabigatran may be affected by humidity; thus, capsules should be kept in the original container or blister package minimizing the exposure to moisture. The content of the bottle expires 60 days after opening. ${ }^{32}$

\section{Dabigatran versus warfarin in patients}

\section{with AF - the RE-LY study}

The RE-LY (randomized evaluation of long-term anticoagulation therapy) study was a randomized noninferiority study designed to investigate the effectiveness of dabigatran for the prevention of stroke and systemic embolism in patients with $\mathrm{AF} .{ }^{33}$ In this study, individuals with nonvalvular AF were randomized to adjusted-dose warfarin with target INR 2.0 to 3.0 or dabigatran in two fixed doses of $110 \mathrm{mg}$ and $150 \mathrm{mg}$ twice daily. The allocation to warfarin or to the investigational drug was open label and the assignment to the two doses of dabigatran was double blind. Participants had nonvalvular AF and at least one additional vascular risk factor, including previous stroke or transient ischemic attack, systemic embolism, heart failure, age $\geq 75$ years, or age 65-74 years and diabetes mellitus, hypertension, or coronary artery disease. Major exclusion criteria included severe valvular disease, stroke within 14 days or severe stroke within 6 months prior to screening, high risk for bleeding, active liver disease, creatine clearance $(\mathrm{CrCl}) \leq 30 \mathrm{~mL} /$ minute, contraindication to warfarin treatment, uncontrolled hypertension, need for anticoagulant treatment of disorders other than AF, and pregnancy. The primary endpoint was the composite of stroke (both ischemic and hemorrhagic) or systemic embolism, and the primary safety outcome was major hemorrhage, defined as reduction in hemoglobin of at least $2 \mathrm{~g} / \mathrm{dL}$, the need of transfusion of at least two units of blood, or symptomatic hemorrhage in a critical area or organ.

A total of 18,113 individuals participated in this study. The median follow-up period was 2 years and more than $99 \%$ of them achieved complete follow-up. The three groups were well balanced by baseline characteristics including vascular risks factors, type of AF, previous use of warfarin, and $\mathrm{CHADS}_{2}$ score $($ mean $=2.1)$. The annual rate for the primary outcome was $1.54 \%$ in the $110 \mathrm{mg}$ arm, $1.11 \%$ in the $150 \mathrm{mg}$ arm, and $1.71 \%$ in the warfarin arm. ${ }^{34}$ Based on the noninferiority margin of 1.46 proposed by the study group, the $110 \mathrm{mg}$ dose (RR 0.91, 95\% CI 0.74-1.11; $P<0.001$ ) and $150 \mathrm{mg}$ dose of dabigatran (RR 0.66, 95\% CI $0.53-0.82 ; P<0.001$ ) were noninferior to warfarin for the primary outcome. ${ }^{34}$ In the superiority analysis, only the $150 \mathrm{mg}$ dose of dabigatran was superior to warfarin $(P<0.001)$. Both doses of dabigatran had a lower rate of hemorrhagic stroke compared to warfarin $(P<0.001)$, and the $150 \mathrm{mg}$ dose - but not the $110 \mathrm{mg}$ dose - was superior to warfarin for preventing stroke of all types, ischemic or unspecified stroke, disabling or fatal stroke, and death from vascular causes (Table 2). Compared to warfarin, the annual rate of major bleeding was lower in the $110 \mathrm{mg}$ group (RR $0.80,95 \%$ CI $0.69-0.93, P=0.003$ ) and not significantly different in the $150 \mathrm{mg}$ group (RR 0.93, 95\% CI 0.81-1.07, $P=0.31$ ). In addition, both doses had a lower annual rate of minor bleeding, intracranial bleeding, and life threatening bleeding than warfarin. In secondary analyses, the results of RE-LY were not influenced by the previous exposure to warfarin or history of stroke or transient ischemic attack. ${ }^{35,36}$ Previous studies have shown that AF patients of Asian background have a higher rate of anticoagulation-associated intracerebral hemorrhage than those of European descent. ${ }^{37}$ In RE-LY, however, the efficacy and safety outcomes were consistent among individuals of different backgrounds, including the Japanese cohort. ${ }^{38}$ Particular subgroups may be at risk of having complications. For example, dabigatran exposure is increased in renal impairment and, in RE-LY, patients assigned to the $150 \mathrm{mg}$ group had a higher rate of myocardial infarction $(0.74 \%$ versus $0.53 \%)$, discontinuation due to gastrointestinal bleeding ( $1.3 \%$ versus $0.9 \%)$, and increased occurrence of gastrointestinal symptoms including 
Table 2 Primary efficacy and safety outcomes of RE-LY

\begin{tabular}{|c|c|c|c|c|c|}
\hline & $\begin{array}{l}\text { Dabigatran II } 0 \text { mg } \\
(\mathrm{n}=6,0 \mid 5) \\
\% \text { lyear }\end{array}$ & $\begin{array}{l}\text { Dabigatran } 150 \mathrm{mg} \\
(\mathrm{n}=6,076) \\
\% \text { lyear }\end{array}$ & $\begin{array}{l}\text { Warfarin } \\
(n=6,022) \\
\% \text { lyear }\end{array}$ & $\begin{array}{l}\text { Dabigatran I I0 mg } \\
\text { versus warfarin } \\
\text { RR }(95 \% \mathrm{Cl})\end{array}$ & $\begin{array}{l}\text { Dabigatran I } 50 \mathrm{mg} \\
\text { versus warfarin } \\
\mathbf{R R}(95 \% \mathrm{Cl})\end{array}$ \\
\hline \multicolumn{6}{|l|}{ Efficacy } \\
\hline $\begin{array}{l}\text { Stroke or systemic } \\
\text { embolism }\end{array}$ & 1.54 & I.II & I.7I & $0.90(0.74-I .10) P=0.30$ & $0.65(0.52-0.8 \mathrm{I}) P<0.00 \mathrm{I}$ \\
\hline \multicolumn{6}{|l|}{ Stroke } \\
\hline Any type & $\mathrm{I} .44$ & 1.01 & 1.57 & $0.92(0.74-I .13) P=0.4 \mathrm{I}$ & $0.64(0.5 I-0.8 I) P<0.00 I$ \\
\hline Hemorrhagic & 0.12 & 0.10 & 0.38 & $0.3 \mathrm{I}(0.17-0.56) P<0.00 \mathrm{I}$ & $0.26(0.14-0.49) P<0.001$ \\
\hline Ischemic or unspecified & 1.34 & 0.92 & 1.20 & I.II (0.89-I.40) $P=0.35$ & $0.76(0.60-0.98) P=0.03$ \\
\hline Nondisabling & 0.50 & 0.37 & 0.58 & $0.86(0.6 \mathrm{I}-\mathrm{I} .22) P=0.40$ & $0.62(0.43-0.9 \mathrm{I}) P=0.0 \mathrm{I}$ \\
\hline Disabling or fatal & 0.94 & 0.66 & 1.00 & $0.94(0.73-1.22) P=0.65$ & $0.66(0.50-0.88) P=0.005$ \\
\hline $\begin{array}{l}\text { Death from vascular } \\
\text { causes }\end{array}$ & 2.43 & 2.88 & 2.69 & $0.90(0.77-1.06) P=0.21$ & $0.85(0.72-0.99) P=0.04$ \\
\hline \multicolumn{6}{|l|}{ Safety } \\
\hline Major bleeding & 2.87 & 3.32 & 3.57 & $0.80(0.70-0.93) P=0.003$ & $0.93(0.8 \mathrm{I}-\mathrm{I} .07) P=0.32$ \\
\hline Intracranial hemorrhage & 0.23 & 0.30 & 0.74 & $0.3 \mathrm{I}(0.20-0.47) P<0.00 \mathrm{I}$ & $0.40(0.27-0.60) P<0.001$ \\
\hline
\end{tabular}

Notes: Data obtained from Connolly et a ${ }^{33}$ and Connolly et a ${ }^{34}$.

pain, vomiting, or diarrhea ( $2.1 \%$ versus $0.6 \%)$ than those receiving warfarin. ${ }^{28,33}$ The higher rate of gastrointestinal complications observed in the dabigatran group has been attributed to its tartaric acid formulation.

The results of RE-LY suggest that dabigatran is an alternative to warfarin for the management of patients with AF. While the $110 \mathrm{mg}$ dose was safer, the $150 \mathrm{mg}$ dose was superior to warfarin in the prevention of stroke and systemic embolism. The superiority of dabigatran has, however, been questioned. The dose of warfarin is adjusted based on the INR, and TTR is commonly used to assess the overall quality of anticoagulation. In RE-LY, the median TTR was $64 \%$ which is in agreement with what has been observed in other large studies utilizing warfarin. ${ }^{39,40}$ In a post-hoc analysis performed to investigate if the results of RE-LY were influenced by optimal INR control, centers with low TTR had a higher rate of major bleeding, all cardiovascular events, and mortality. ${ }^{41}$ These results suggest that local standards of care may have influenced some of the outcomes of RE-LY. In addition, they indicate that while dabigatran $110 \mathrm{mg}$ twice daily may be safer and $150 \mathrm{mg}$ twice daily may be superior to warfarin in a large population, this may not be the case for an individual patient, particularly in those cases with excellent INR control.

The $110 \mathrm{mg}$ dose of dabigatran showed a trend towards causing a lower rate of major hemorrhage than the $150 \mathrm{mg}$ dose (RR 1.16, 95\% CI 1.00-1.34; $P=0.052$ ), suggesting that a lower dose may be a better option for individuals considered at risk of bleeding, such as the elderly and those individuals with impaired kidney function, or for those who bled while receiving the higher dose of dabigatran. Subgroup analyses, however, showed that the rate of stroke in AF patients $\geq 75$ years of age was lower with the $150 \mathrm{mg}$ dose than with the $110 \mathrm{mg}$ dose (1.4 versus 1.9 per 100 patient-years), but the rate of hemorrhage was higher (5.1 versus 4.4 per 100 patientyears) with a similar risk-benefit ratio. In addition, the rate of bleeding in the subgroup of patients with impaired renal function $(\mathrm{CrCl}>30-50 \mathrm{~mL} /$ minute $)$ was similar for both doses of dabigatran..$^{42}$ Furthermore, the rates of additional major bleeds across all three treatment groups in subjects who had a major bleed and either continued or resumed the study medication were similar. ${ }^{31}$ In this setting, it has been argued that it may be unethical to start a naïve patient on the lower dose of dabigatran.

Dabigatran is commercially available in the United States under the name of Pradaxa ${ }^{\circledR}$ and, based on the results of the study RE-LY, it was approved by the Food and Drug Administration Cardiovascular and Renal Drugs Advisory Committee in September 2010 for the prevention of stroke and non-CNS systemic embolism in patients with nonvalvular $\mathrm{AF}^{31}$ The approved doses are $150 \mathrm{mg}$ twice daily for individuals with $\mathrm{CrCl}>30 \mathrm{~mL} /$ minute and $75 \mathrm{mg}$ twice daily for those with $\mathrm{CrCl} 15-30 \mathrm{~mL} /$ minute. As aforementioned, subgroup analyses failed to identify a particular group of patients that could benefit from using the lower dose of dabigatran. In this setting, the dose of $110 \mathrm{mg}$ twice daily did not receive Food and Drug Administration approval to be commercialized in the United States for the prevention of stroke in AF. Differently, the European Medicines Agency and the Canadian health authority, Health Canada, approved both the $150 \mathrm{mg}$ and the $110 \mathrm{mg}$ twice daily doses. In Canada, the lower dose is specifically available for individuals older 
than 80 years of age and for those over the age of 75 at risk of bleeding. ${ }^{43,44}$

In light of the effects observed in animal models, the use of dabigatran during pregnancy is considered off-label. ${ }^{31}$ In 2011, the American Heart Association, the American College of Cardiology Foundation, and the Heart Rhythm Society updated the practice guidelines for the management of patients with AF and incorporated dabigatran as an "alternative to warfarin for the prevention of stroke and systemic thromboembolism in patients with $\mathrm{AF}$ and risk factor for stroke or systemic embolization who do not have prosthetic heart valve, hemodynamically significant valve disease, severe renal failure $(\mathrm{CrCl}<15 \mathrm{~mL} /$ minute $)$, or advanced liver disease". 45

\section{Coagulation assays and reversal of dabigatran effect}

Unlike classic anticoagulants, dabigatran has a predictable pharmacology, a low number of interactions, and does not require routine laboratory monitoring. A close correlation exists between the anticoagulation effect and the plasma levels of dabigatran and, based on the results of the PETRO (prevention of embolic and thrombotic events) study, patients with AF treated with dabigatran $150 \mathrm{mg}$ twice a day have a $\mathrm{C}_{\max }$ of $184 \mathrm{ng} / \mathrm{mL}$ and a concentration before dosing $\left(\mathrm{C}_{\text {trough }}\right)$ of $90 \mathrm{ng} / \mathrm{mL} .{ }^{46}$ At this dose, dabigatran affects coagulation assays typically used in clinical practice; the extent of the effect, however, may be influenced by the time of blood sampling relative to the administration of the drug. ${ }^{47}$ The prothrombin time (PT) is utilized in clinical practice to evaluate the extrinsic coagulation pathway. Increasing doses of dabigatran have been shown to have a linear correlation with $\mathrm{PT} ;{ }^{48}$ however, this test is considered relatively insensitive to determine the plasma activity of dabigatran as therapeutic doses result in a modest prolongation in the PT, and supratherapeutic doses cause only a twofold increase in the INR. ${ }^{48}$ Conversely, the activated partial thromboplastin time (aPTT) assesses the intrinsic coagulation pathway. A therapeutic dose of $150 \mathrm{mg}$ twice daily results in a twofold increase in the aPTT and the dose-response curve is curvilinear flattening at plasma levels of $200 \mathrm{ng} / \mathrm{mL} .{ }^{47}$ Though this test is suboptimal to measure the effect of dabigatran, particularly at high doses, a prolonged aPTT time suggests the patient has significant circulating levels of the drug and, thus, can be used in emergency situations as a qualitative hemostatic marker. The thrombin clotting time (TT) and its diluted version, the Hemoclot ${ }^{\circledR}$, measure time to clot formation in a sample of plasma incubated in the presence of exogenous thrombin. These tests have a very good sensitivity to assess the plasma activity of DTI and both have linear dose-response curves with therapeutic and supratherapeutic doses of dabigatran. ${ }^{49,50}$ The ecarin clotting time (ECT) utilizes ecarin, a purified metalloprotease isolated from the venom of Echis carinatus, to convert prothrombin to meizothrombin; this is an unstable precursor of thrombin that subsequently leads to clot formation. DTI inhibit thrombin-like activity and the administration of dabigatran $150 \mathrm{mg}$ twice daily has been shown to lead to a two- to four-fold increase in the ECT compared to baseline. ${ }^{24,51}$ The ECT is considered a specific DTI test as it is not affected by heparin or vitamin $\mathrm{K}$ inhibitors. TT, Hemoclot ${ }^{\circledR}$, and ECT, however, have not been standardized or validated in large cohorts and their use should be considered largely investigational.

In cases of elective surgery, dabigatran may need to be temporarily discontinued. Based on the $t_{1 / 2}$, the manufacturer recommends holding it for 1-2 days ( $\mathrm{CrCl} \geq 50 \mathrm{~mL} / \mathrm{minute}$ ), $3-5$ days ( $\mathrm{CrCl}<50 \mathrm{~mL} / \mathrm{minute}$ ), or $>5$ days $(\mathrm{CrCl}<30 \mathrm{~mL} /$ minute $)$ before the procedure. These times may be longer in patients at high risk of bleeding or those cases requiring complete hemostasis. If an urgent intervention is required, it is advised to delay the procedure at least 12 hours after the last dose of dabigatran. ${ }^{30}$ In emergency circumstances the effect of dabigatran may need to be reversed. While DTI do not have specific antidotes, the low tissue accumulation and plasma protein binding of dabigatran indicate this drug may be dialyzable. In a small study including 23 subjects with different degrees of renal disease, the mean fraction of the circulating dabigatran removed by hemodialysis was $62 \%$ to $68 \%$. Studies in animal models have shown that the effect of this drug on bleeding time and aPTT can be antagonized by recombinant activated factor VII (NovoSeven ${ }^{\circledR}$ ) or activated prothrombin complex concentrate $\left(\right.$ Feiba $\left.\mathrm{VH}^{\circledR}\right) .{ }^{52,53}$ While promising, further studies in human subjects are needed to define the efficacy and safety of these products in reversing the effect of dabigatran in patients with AF.

\section{Cost-effectiveness analysis}

The cost-effectiveness analysis of dabigatran versus warfarin is complex as both drugs have different drivers. Warfarin is a relatively inexpensive medication with once a day dosing; however, it requires frequent INR monitoring, has multiple drug and food interactions and, in specific cases, may require frequent dose adjustments increasing the risk for errors and time outside of the target INR 2.0 to 3.0. These factors may, at least in part, explain the results obtained in observational studies which show that only half of the warfarin-eligible 
patients are treated with this drug in real life. ${ }^{54,55}$ In contrast, dabigatran is more expensive but easier to utilize as it has a fixed dose, no food and few drug interactions, some of which may not be clinically relevant, and does not require routine laboratory monitoring. In addition, by reducing the rate of ischemic and hemorrhagic stroke, dabigatran may reduce both direct (eg, inpatient care, rehabilitation, follow-up care) and indirect (eg, long-term disability, lost years of productivity) costs associated with AF complications.

In a Canadian study, incremental quality-adjusted life years (QALYs) and incremental cost effectiveness ratios (ICER) were obtained for dabigatran and warfarin in two anticoagulation scenarios: "trial-like" and "real-world". In the "trial-like" construct, quality of INR control was based on the TTR of $64 \%$ observed in RE-LY; in the "real-world" model, time spent within or outside of the therapeutic INR range was based on the data obtained from retrospective observational studies performed in the general public. ${ }^{56}$ According to this study, the incremental QALYs and ICER in "trial-like" conditions for dabigatran versus warfarin were 0.21 and CA $\$ 10,440$, respectively. In comparison, the incremental QALYs and ICER in "real-world" conditions, where intensity and quality of anticoagulation are not as well controlled as in a trial, were 0.28 and CA $\$ 3,962$, respectively. These estimates suggest that dabigatran is a cost-effective alternative to warfarin for the prevention of stroke or systemic embolism in AF patients in Canada. Cost-effectiveness largely depends on drug pricing. Compared to the results obtained in Canada and based on the cost of dabigatran in the United Kingdom, it has been estimated that the incremental QALY with dabigatran $150 \mathrm{mg}$ twice daily versus warfarin is 0.56 and the ICER US\$45,372. ${ }^{57}$

\section{Factor Xa inhibitors}

The results of several promising trials designed to investigate the efficacy of other novel oral anticoagulants in the prevention of embolic complications in patients with AF have recently been released.

\section{Apixaban}

Apixaban is an oral inhibitor of factor Xa that does not require frequent INR monitoring and has fewer interactions than warfarin. The Apixaban Versus Acetylsalicylic Acid (ASA) to Prevent Stroke in Atrial Fibrillation Patients Who Have Failed or Are Unsuitable for Vitamin K Antagonist Treatment (AVERROES) study was designed to compare the efficacy of apixaban (5 mg twice daily) with aspirin (81-324 mg per day) in the prevention of embolism in patients with $\mathrm{AF}$ who were not candidates for treatment with vitamin $\mathrm{K}$ antagonists. ${ }^{58}$ Patients were eligible to participate in this study if they had $\mathrm{AF}$ and at least one of the following risk factors for stroke: hypertension, age $\geq 75$ years, diabetes, heart failure, or peripheral artery disease. This study was terminated early because of a clear benefit in favor of apixaban. The annual rate for the primary outcome, defined as stroke or systemic embolism, was $1.6 \%$ per year for patients receiving apixaban and $3.7 \%$ per year for patients receiving aspirin (hazard ratio [HR] $0.45 ; 95 \%$ CI $0.32-0.62 ; P<0.001$ for superiority). The rates of major bleeding and intracranial hemorrhage were similar between both groups, suggesting that apixaban is a better alternative to aspirin for the prevention of stroke and systemic embolism in patients with AF in whom vitamin $\mathrm{K}$ antagonists are unsuitable. In light of the results obtained in AVERROES, the future role of aspirin in the management of AF patients with $\mathrm{CHADS}_{2}$ score $\geq 1$ is uncertain and likely to be reduced to a selected subgroup of individuals deemed unsuitable for any type of oral anticoagulant.

\section{Rivaroxaban}

Rivaroxaban is an oral factor Xa inhibitor that, similar to apixaban, does not require laboratory monitoring and has fewer drug and food interactions than warfarin. ROCKET-AF (rivaroxaban-once daily, oral, direct factor Xa inhibition compared with vitamin $\mathrm{K}$ antagonism for prevention of stroke and embolism trial in AF) was a noninferiority study designed to compare the efficacy of a fixed dose of rivaroxaban $(20 \mathrm{mg}$ once daily) to dose-adjusted warfarin with an INR target 2.0 to 3.0 for the prevention of stroke or systemic embolism in patients with nonvalvular AF and $\mathrm{CHADS}_{2}$ score $\geq 2 .{ }^{59}$ The preliminary results presented at the 2010 American Heart Association Scientific Sessions showed that the rate for the primary outcome of stroke or non-CNS systemic embolism was 1.71 per 100 patient-years in the rivaroxaban arm and 2.16 per 100 patient-years in the warfarin arm (HR 0.79; $95 \%$ CI $0.66-0.96 ; P<0.001$ for noninferiority).$^{40}$ The primary safety outcome measure, defined as major bleeding and the rate of major and non-major bleeding were not statistically different among both groups, and the rate of intracranial hemorrhage was lower in the rivaroxaban group (HR 0.67; 95\% CI 0.47-0.94; $P=0.019)$. The results of ROCKET-AF showed that rivaroxaban, similar to dabigatran, is safe and noninferior to warfarin for the prevention of stroke and systemic embolism in patients with AF. It should be noted, however, that rivaroxaban was superior to warfarin only in the per-protocol analysis but not in the intention-to-treat analysis. 
Studies performed in animal models suggest that apixaban, rivaroxaban, and dabigatran have similar efficacy in preventing venous thrombosis. ${ }^{60}$ However, the efficacy of oral factor Xa inhibitors and DTI in the prevention of embolism in patients with AF has not been investigated in head to head trials and indirect comparisons are limited due to the presence of confounders and methodological differences among the studies. For example, compared to RE-LY, patients in ROCKET-AF had a higher average $\mathrm{CHADS}_{2}$ score (3.5 versus 2.1 ) but a shorter TTR $(57.8 \%$ versus $64 \%) .{ }^{33,40}$ In addition, both studies utilized different inclusion criteria and safety outcomes. Two additional phase III randomized, double-blind, noninferiority studies are currently underway to compare the effectiveness of the oral factor Xa inhibitors apixaban (ARISTOTLE; apixaban for reduction in stroke and other thromboembolic events) and edoxaban (ENGAGE AF-TIMI 48; effective anticoagulation with factor Xa next generation in AF-thrombolysis in myocardial infarction study 48) to adjusted-dose warfarin with a target INR 2.0 to 3.0 in the prevention of stroke or embolism in $\mathrm{AF}^{61,62}$ The general characteristics of these trials have been summarized in Table 3.

As our armamentarium to prevent stroke and embolism in patients with AF continues to expand, physicians may

Table 3 Trials of new oral anticoagulants in the prevention of stroke in AF patients

\begin{tabular}{|c|c|c|c|c|c|c|}
\hline \multirow[t]{2}{*}{ Study } & \multirow[t]{2}{*}{ Design } & \multirow{2}{*}{$\begin{array}{l}\text { Study } \\
\text { size }\end{array}$} & \multirow[t]{2}{*}{ Patients } & \multirow[t]{2}{*}{ Intervention } & \multicolumn{2}{|l|}{ Outcome } \\
\hline & & & & & Efficacy & Safety \\
\hline $\begin{array}{l}\text { RE-LY }{ }^{33} \text { Dabigatran } \\
\text { (DTI) }\end{array}$ & $\begin{array}{l}\text { Randomized, open } \\
\text { label, noninferiority }\end{array}$ & 18,113 & $\begin{array}{l}\text { AF plus } \geq \text { I risk } \\
\text { factor for stroke }\end{array}$ & $\begin{array}{l}\text { Dabigatran I I } 0 \text { mg twice } \\
\text { daily versus dabigatran } \\
\text { I } 50 \mathrm{mg} \text { twice daily versus } \\
\text { warfarin (INR } 2.0 \text { to } 3.0 \text { ) }\end{array}$ & $\begin{array}{l}\text { Stroke or } \\
\text { systemic } \\
\text { embolism }\end{array}$ & $\begin{array}{l}\text { Major bleeding (reduction in } \\
\mathrm{Hb} \text { level } \geq 2 \mathrm{~g} / \mathrm{dL} \text {, transfusion } \\
\text { of } \geq 2 \text { units of blood, life- } \\
\text { threatening, or symptomatic } \\
\text { bleeding in a critical area or } \\
\text { organ) }\end{array}$ \\
\hline $\begin{array}{l}\text { ROCKET-AF } 59 \\
\text { Rivaroxaban (FXal) }\end{array}$ & $\begin{array}{l}\text { Randomized, double } \\
\text { blind, double dummy, } \\
\text { noninferiority }\end{array}$ & 14,266 & $\begin{array}{l}\text { AF plus } \geq 2 \text { risk } \\
\text { factors for stroke }\end{array}$ & $\begin{array}{l}\text { Rivaroxaban } 20 \text { mg daily } \\
\text { plus warfarin placebo } \\
\text { versus warfarin (INR } 2.0 \\
\text { to } 3.0 \text { ) plus rivaroxaban } \\
\text { placebo }\end{array}$ & $\begin{array}{l}\text { Stroke or } \\
\text { systemic } \\
\text { embolism }\end{array}$ & $\begin{array}{l}\text { Major and nonmajor clinically } \\
\text { relevant bleeding }\end{array}$ \\
\hline $\begin{array}{l}\text { ARISTOTLE }{ }^{61} \\
\text { Apixaban (FXal) }\end{array}$ & $\begin{array}{l}\text { Randomized, double } \\
\text { blind, double dummy, } \\
\text { noninferiority }\end{array}$ & 15,000 & $\begin{array}{l}\text { AF plus } \geq \text { I risk } \\
\text { factor for stroke }\end{array}$ & $\begin{array}{l}\text { Apixaban } 5 \mathrm{mg} \text { twice } \\
\text { a day plus warfarin placebo } \\
\text { versus warfarin } \\
\text { (INR } 2.0 \text { to } 3.0 \text { ) plus } \\
\text { apixaban placebo }\end{array}$ & $\begin{array}{l}\text { Stroke or } \\
\text { systemic } \\
\text { embolism }\end{array}$ & $\begin{array}{l}\text { Clinically overt bleeding } \\
\text { accompanied by } \geq 1 \text { of the } \\
\text { following: reduction in } \mathrm{Hb} \\
\text { level } \geq 2 \mathrm{~g} / \mathrm{dL} \text { over } 24 \text { hours, } \\
\text { transfusion of } \geq 2 \text { units of } \\
\text { blood, or bleeding that is fatal } \\
\text { or occurs in a critical area } \\
\text { or organ }\end{array}$ \\
\hline $\begin{array}{l}\text { AVERROES } 58 \\
\text { Apixaban (FXal) }\end{array}$ & $\begin{array}{l}\text { Randomized, double } \\
\text { blind, double dummy, } \\
\text { superiority }\end{array}$ & 5,600 & $\begin{array}{l}\text { AF plus } \geq \text { I risk } \\
\text { factor for stroke, } \\
\text { patients were } \\
\text { unsuitable to } \\
\text { receive warfarin }\end{array}$ & $\begin{array}{l}\text { Apixaban } 5 \mathrm{mg} \text { twice } \\
\text { a day versus aspirin }\end{array}$ & $\begin{array}{l}\text { Stroke or } \\
\text { systemic } \\
\text { embolism }\end{array}$ & $\begin{array}{l}\text { Clinically overt bleeding } \\
\text { accompanied by } \geq \mathrm{I} \text { of the } \\
\text { following: reduction in } \mathrm{Hb} \\
\text { level } \geq 2 \mathrm{~g} / \mathrm{dL} \text { over } 24 \text { hours, } \\
\text { transfusion of } \geq 2 \text { units of } \\
\text { blood, or bleeding that is fatal } \\
\text { or occurs in a critical area } \\
\text { or organ }\end{array}$ \\
\hline $\begin{array}{l}\text { ENGAGE } \\
\text { AF-TIMI } 48^{62} \\
\text { Edoxaban (FXal) }\end{array}$ & $\begin{array}{l}\text { Randomized, double } \\
\text { blind, double dummy, } \\
\text { noninferiority }\end{array}$ & 16,500 & $\begin{array}{l}\text { AF plus } \geq \text { I risk } \\
\text { factor for stroke }\end{array}$ & $\begin{array}{l}\text { Edoxaban plus warfarin } \\
\text { placebo versus warfarin } \\
\text { (INR } 2.0 \text { to } 3.0 \text { ) plus } \\
\text { edoxaban placebo }\end{array}$ & $\begin{array}{l}\text { Stroke or } \\
\text { systemic } \\
\text { embolism }\end{array}$ & $\begin{array}{l}\text { Clinically overt bleeding } \\
\text { accompanied by } \geq \mathrm{I} \text { of the } \\
\text { following: reduction in } \mathrm{Hb} \\
\text { level } \geq 2 \mathrm{~g} / \mathrm{dL} \text { over } 24 \text { hours, } \\
\text { transfusion of } \geq 2 \text { units of } \\
\text { blood, or bleeding that is fatal } \\
\text { or occurs in a critical area } \\
\text { or organ }\end{array}$ \\
\hline
\end{tabular}

Abbreviations: AF, atrial fibrillation; ARISTOTLE, apixaban for reduction in stroke and other thromboembolic events in atrial fibrillation; AVERROES, apixaban versus acetylsalicylic acid to prevent stroke in atrial fibrillation patients who have failed or are unsuitable for vitamin $\mathrm{K}$ antagonist treatment; DTI, direct thrombin inhibitor; ENGAGE AF-TIMI 48, evaluation of the novel factor Xa inhibitor edoxaban compared with warfarin in patients with atrial fibrillation: design and rationale for the effective anticoagulation with factor Xa next generation in atrial fibrillation-thrombolysis in myocardial infarction study 48; FXal, factor Xa inhibitor; Hb, hemoglobin; INR, international normalized ratio; RE-LY, randomized evaluation of long-term anticoagulation therapy; ROCKET-AF, rivaroxaban once daily, oral, direct factor Xa inhibition compared with vitamin $\mathrm{K}$ antagonism for prevention of stroke and embolism trial in atrial fibrillation. 
in the future have the option to tailor the anticoagulation approach to each individual case. For example, dabigatran may not be the optimal option to treat individuals with severe renal disease. Conversely, apixaban and rivaroxaban may be more susceptible than dabigatran to drug interactions as their pharmacokinetic profiles can be affected by inducers and inhibitors of CYP3A4 and P-glycoprotein efflux pump. ${ }^{63}$

\section{Conclusion}

Several new oral anticoagulants have been recently developed. The results of RE-LY indicate that dabigatran is a safe and efficacious alternative to warfarin for the prevention of stroke and systemic embolism in patients with AF. Based on the lower rate of embolic events observed in individuals on the $150 \mathrm{mg}$ dose of dabigatran, physicians may opt to use this drug in warfarin-naïve patients, particularly in those with unstable INR, limited access to laboratory monitoring, and those taking medications that may interact with vitamin $\mathrm{K}$ inhibitors. The noninferiority of dabigatran compared to warfarin in individuals with good INR control has been questioned based on the TTR of $64 \%$ seen in the RE-LY trial. Thus, physicians may consider using warfarin in individuals who are stable on this medication and have optimal INR control. In addition, the higher rate of myocardial infarction and gastrointestinal complications observed in patients treated with dabigatran deserves further investigation and caution should be exercised in these particular subgroups. The results of the completed trials suggest that oral factor Xa inhibitors, particularly rivaroxaban, are additional alternatives to warfarin for the prevention of stroke in AF. While initial results are encouraging, it remains to be seen if these agents will be able to replace traditional anticoagulants in the treatment of AF. Head to head comparisons between different new oral anticoagulants will also need to be performed to determine the winner of the race for the most effective and safe anticoagulant.

\section{Disclosure}

The authors report no conflicts of interest in this work.

\section{References}

1. Miyasaka Y, Barnes ME, Gersh BJ, et al. Secular trends in incidence of atrial fibrillation in Olmsted County, Minnesota, 1980 to 2000, and implications on the projections for future prevalence. Circulation. 2006;114(2):119-125.

2. Lakshminarayan K, Solid CA, Collins AJ, Anderson DC, Herzog CA. Atrial fibrillation and stroke in the general medicare population: a 10-year perspective (1992 to 2002). Stroke. 2006;37(8):1969-1974.

3. Ezekowitz MD. Atrial fibrillation: the epidemic of the new millennium. Ann Intern Med. 1999;131(7):537-538.
4. Roger VL, Go AS, Lloyd-Jones DM, et al. Heart disease and stroke statistics - 2011 update: a report from the American Heart Association. Circulation. 2011;123(4):e18-e209.

5. Kwok CS, Loke YK, Hale R, Potter JF, Myint PK. Atrial fibrillation and incidence of dementia: a systematic review and meta-analysis. Neurology. 2011;76(10):914-922.

6. Wolf PA, Abbott RD, Kannel WB. Atrial fibrillation as an independent risk factor for stroke: the Framingham Study. Stroke. 1991;22(8): 983-988.

7. Gage BF, Waterman AD, Shannon W, Boechler M, Rich MW, Radford MJ. Validation of clinical classification schemes for predicting stroke: results from the National Registry of Atrial Fibrillation. JAMA. 2001;285(22):2864-2870.

8. Stroke Risk in Atrial Fibrillation Working Group. Comparison of 12 risk stratification schemes to predict stroke in patients with nonvalvular atrial fibrillation. Stroke. 2008;39(6):1901-1910.

9. Lip GY, Halperin JL. Improving stroke risk stratification in atrial fibrillation. Am J Med. 2010;123(6):484-488.

10. Lip GY, Nieuwlaat R, Pisters R, Lane DA, Crijns HJ. Refining clinical risk stratification for predicting stroke and thromboembolism in atrial fibrillation using a novel risk factor-based approach: the euro heart survey on atrial fibrillation. Chest. 2010;137(2):263-272.

11. European Heart Rhythm Association, European Association for CardioThoracic Surgery; Camm AJ, Kirchhof P, Lip GY, et al. Guidelines for the management of atrial fibrillation: the Task Force for the Management of Atrial Fibrillation of the European Society of Cardiology (ESC). Eur Heart J. 2010;31(19):2369-2429.

12. Fuster V, Ryden LE, Cannom DS, et al. 2011 ACCF/AHA/HRS focused updates incorporated into the ACC/AHA/ESC 2006 guidelines for the management of patients with atrial fibrillation: a report of the American College of Cardiology Foundation/American Heart Association Task Force on practice guidelines. Circulation. 2011;123(10): e269-e367.

13. Hart RG, Pearce LA, Aguilar MI. Meta-analysis: antithrombotic therapy to prevent stroke in patients who have nonvalvular atrial fibrillation. Ann Intern Med. 2007;146(12):857-867.

14. Waldo AL, Becker RC, Tapson VF, Colgan KJ. NABOR Steering Committee. Hospitalized patients with atrial fibrillation and a high risk of stroke are not being provided with adequate anticoagulation. J Am Coll Cardiol. 2005;46(9):1729-1736.

15. Lip GY, Frison L, Halperin JL, Lane DA. Comparative validation of a novel risk score for predicting bleeding risk in anticoagulated patients with atrial fibrillation: the HAS-BLED (Hypertension, Abnormal Renal/ Liver Function, Stroke, Bleeding History or Predisposition, Labile INR, Elderly, Drugs/Alcohol Concomitantly) score. J Am Coll Cardiol. 2011;57(2):173-180.

16. Ellis DJ, Usman MH, Milner PG, Canafax DM, Ezekowitz MD. The first evaluation of a novel vitamin $\mathrm{K}$ antagonist, tecarfarin (ATI5923 ), in patients with atrial fibrillation. Circulation. 2009;120(12): 1029-1035.

17. Goldstein LB, Bushnell CD, Adams RJ, et al. Guidelines for the primary prevention of stroke: a guideline for healthcare professionals from the American Heart Association/American Stroke Association. Stroke. 2011;42(2):517-584.

18. Furie KL, Kasner SE, Adams RJ, et al. American Heart Association Stroke Council, Council on Cardiovascular Nursing, Council on Clinical Cardiology, and Interdisciplinary Council on Quality of Care and Outcomes Research. Guidelines for the prevention of stroke in patients with stroke or transient ischemic attack: a guideline for healthcare professionals from the American Heart Association/American Stroke Association. Stroke. 2011;42(1):227-276.

19. Mant J, Hobbs FD, Fletcher K, et al. BAFTA investigators, Midland Research Practices Network (MidReC). Warfarin versus aspirin for stroke prevention in an elderly community population with atrial fibrillation (the Birmingham Atrial Fibrillation Treatment of the Aged Study, BAFTA): a randomised controlled trial. Lancet. 2007;370(9586): 493-503. 
20. ACTIVE Writing Group of the ACTIVE Investigators; Connolly S, Pogue J, Hart R, et al. Clopidogrel plus aspirin versus oral anticoagulation for atrial fibrillation in the Atrial fibrillation Clopidogrel Trial with Irbesartan for prevention of Vascular Events (ACTIVE W): a randomised controlled trial. Lancet. 2006;367(9526):1903-1912.

21. ACTIVE Investigators; Connolly SJ, Pogue J, Hart RG, et al. Effect of clopidogrel added to aspirin in patients with atrial fibrillation. $N$ Engl J Med. 2009;360(20):2066-2078.

22. Akins PT, Feldman HA, Zoble RG, et al. Secondary stroke prevention with ximelagatran versus warfarin in patients with atrial fibrillation: pooled analysis of SPORTIF III and V clinical trials. Stroke. 2007;38(3): 874-880.

23. Wienen W, Stassen JM, Priepke H, Ries UJ, Hauel N. In-vitro profile and ex-vivo anticoagulant activity of the direct thrombin inhibitor dabigatran and its orally active prodrug, dabigatran etexilate. Thromb Haemost. 2007;98(1):155-162.

24. Stangier J, Stahle H, Rathgen K, Fuhr R. Pharmacokinetics and pharmacodynamics of the direct oral thrombin inhibitor dabigatran in healthy elderly subjects. Clin Pharmacokinet. 2008;47(1):47-59.

25. European Medicines Agency. Product Information. 2010. Available from: http://www.ema.europa.eu/docs/en_GB/document_library/ EPAR_-_Product_Information/human/000829/WC500041059.pdf. Accessed March 23, 2011.

26. Stangier J, Eriksson BI, Dahl OE, et al. Pharmacokinetic profile of the oral direct thrombin inhibitor dabigatran etexilate in healthy volunteers and patients undergoing total hip replacement. $J$ Clin Pharmacol. 2005;45(5):555-563.

27. Blech S, Ebner T, Ludwig-Schwellinger E, Stangier J, Roth W. The metabolism and disposition of the oral direct thrombin inhibitor, dabigatran, in humans. Drug Metab Dispos. 2008;36(2):386-399.

28. Stangier J, Rathgen K, Stahle H, Mazur D. Influence of renal impairment on the pharmacokinetics and pharmacodynamics of oral dabigatran etexilate: an open-label, parallel-group, single-centre study. Clin Pharmacokinet. 2010;49(4):259-268.

29. Stangier J, Stahle H, Rathgen K, Roth W, Shakeri-Nejad K. Pharmacokinetics and pharmacodynamics of dabigatran etexilate, an oral direct thrombin inhibitor, are not affected by moderate hepatic impairment. J Clin Pharmacol. 2008;48(12):1411-1419.

30. Boehringer-Ingelheim Corporate. Medication Guide. 2011. Available from: http://bidocs.boehringer-ingelheim.com/BIWebAccess/ ViewServlet.ser?docBase=renetnt $\&$ folderPath $=/$ Prescribing $\% 20$ Information/PIs/Pradaxa/Pradaxa.pdf. Accessed May 1, 2011.

31. Food and Drug Administration (FDA). PRADAXA Drug Approval Package. October 19, 2010. Available from: http://www.accessdata.fda. gov/drugsatfda_docs/nda/2010/022512Orig1s000SumR.pdf. Accessed March 25, 2011

32. Food and Drug Administration. Drug Safety Communication. March 29, 2011. Available from: http://www.fda.gov/Drugs/DrugSafety/ ucm248746.htm. Accessed May 1, 2011.

33. Connolly SJ, Ezekowitz MD, Yusuf S, et al; RE-LY Steering Committee and Investigators. Dabigatran versus warfarin in patients with atrial fibrillation. N Engl J Med. 2009;361(12):1139-1151.

34. Connolly SJ, Ezekowitz MD, Yusuf S, Reilly PA, Wallentin L. Randomized Evaluation of Long-Term Anticoagulation Therapy Investigators. Newly identified events in the RE-LY trial. $N$ Engl J Med. 2010;363(19): 1875-1876.

35. Diener HC, Connolly SJ, Ezekowitz MD, et al. RE-LY study group. Dabigatran compared with warfarin in patients with atrial fibrillation and previous transient ischaemic attack or stroke: a subgroup analysis of the RE-LY trial. Lancet Neurol. 2010;9(12):1157-1163.

36. Ezekowitz MD, Wallentin L, Connolly SJ, et al; RE-LY Steering Committee and Investigators. Dabigatran and warfarin in vitamin $\mathrm{K}$ antagonist-naive and -experienced cohorts with atrial fibrillation. Circulation. 2010;122(22):2246-2253.

37. Shen AY, Yao JF, Brar SS, Jorgensen MB, Chen W. Racial/ethnic differences in the risk of intracranial hemorrhage among patients with atrial fibrillation. J Am Coll Cardiol. 2007;50(4):309-315.
38. Hori M, Connolly SJ, Ezekowitz MD, Reilly PA, Yusuf S, Wallentin L. The RE-LY Investigators. Efficacy and safety of dabigatran vs warfarin in patients with atrial fibrillation. Circ J. 2011;75(4): 800-805.

39. Olsson SB; Executive Steering Committee of the SPORTIF III Investigators. Stroke prevention with the oral direct thrombin inhibitor ximelagatran compared with warfarin in patients with non-valvular atrial fibrillation (SPORTIF III): randomised controlled trial. Lancet. 2003;362(9397):1691-1698.

40. Gensch C, Hoppe U, Bohm M, Laufs U. Late-breaking clinical trials presented at the American Heart Association Congress in Chicago 2010. Clin Res Cardiol. 2011;100(1):1-9.

41. Wallentin L, James S, Storey RF, et al. PLATO investigators. Effect of CYP2C19 and ABCB1 single nucleotide polymorphisms on outcomes of treatment with ticagrelor versus clopidogrel for acute coronary syndromes: a genetic substudy of the PLATO trial. Lancet. 2010;376(9749): $1320-1328$.

42. Beasley BN, Unger EF, Temple R. Anticoagulant options - why the FDA approved a higher but not a lower dose of dabigatran. $N$ Engl J Med. 2011;364(19):1788-1790.

43. European Medicines Agency. Summary of opinion on dabigatran. April 14, 2011. Available from: http://www.ema.europa.eu/docs/ en_GB/document_library/Summary_of_opinion/human/000829/ WC500105283.pdf. Accessed May 1, 2011

44. Health Canada. Product Monograph. April 1, 2010. Available from: http://webprod.hc-sc.gc.ca/dpd-bdpp/info.do?lang=eng\&code=79795. Accessed May 1, 2011.

45. Wann LS, Curtis AB, Ellenbogen KA, et al. 2011 ACCF/AHA/HRS focused update on the management of patients with atrial fibrillation (update on dabigatran): a report of the American College of Cardiology Foundation/American Heart Association Task Force on Practice Guidelines. Circulation. 2011;123(10):1144-1150.

46. Ezekowitz MD, Reilly PA, Nehmiz G, et al. Dabigatran with or without concomitant aspirin compared with warfarin alone in patients with nonvalvular atrial fibrillation (PETRO Study). Am J Cardiol. 2007; 100(9):1419-1426.

47. Stangier J, Rathgen K, Stahle H, Gansser D, Roth W. The pharmacokinetics, pharmacodynamics and tolerability of dabigatran etexilate, a new oral direct thrombin inhibitor, in healthy male subjects. Br J Clin Pharmacol. 2007;64(3):292-303.

48. Samama MM, Guinet C. Review: laboratory assessment of new anticoagulants. Clin Chem Lab Med. 2011;49(5):761-772.

49. Mitchell LG, Dietrich K, Stang L, Etches W, Qayyum S. Comparison of hemoclot to standard coagulation assays for monitoring the direct thrombin inhibitor (dabigatran) in pediatric patients: an in vitro study [abstract]. J Thromb Haemost. 2009;7 Suppl 2:777.

50. van Ryn J, Stangier J, Haertter S, et al. Dabigatran etexilate - a novel, reversible, oral direct thrombin inhibitor: interpretation of coagulation assays and reversal of anticoagulant activity. Thromb Haemost. 2010;103(6):1116-1127.

51. Nowak G. The ecarin clotting time, a universal method to quantify direct thrombin inhibitors. Pathophysiol Haemost Thromb. 2003;33(4):173-183.

52. Wienen W, Ruehl D, Stassen JM, Priepke H, Ries UJ, Hauel N. Effect of recombinant factor VIIa or activated prothrombin complex concentrate on the bleeding time in anaesthetized rats during anticoagulant treatment with the direct thrombin inhibitor dabigatran [abstract]. J Thromb Haemost. 2005;3 Suppl 1:P1703.

53. Van Ryn J, Ruehl D, Priepke H, Hauel N, Wienen W. Reversibility of the anticoagulant effect of high doses of the direct thrombin inhibitor dabigatran, by recominant factro VIIa or activated prothrombin complex concentrate. [abstract]. Haematologica. 2008;93 Suppl 1: 148.

54. Friberg L, Hammar N, Ringh M, Pettersson H, Rosenqvist M. Stroke prophylaxis in atrial fibrillation: who gets it and who does not? Report from the Stockholm Cohort-study on Atrial Fibrillation (SCAF-study). Eur Heart J. 2006;27(16):1954-1964. 
55. Partington SL, Abid S, Teo K, Oczkowski W, O’Donnell MJ. Pre-admission warfarin use in patients with acute ischemic stroke and atrial fibrillation: The appropriate use and barriers to oral anticoagulant therapy. Thromb Res. 2007;120(5):663-669.

56. Sorensen SV, Kansal AR, Connolly S, et al. Cost-effectiveness of dabigatran etexilate for the prevention of stroke and systemic embolism in atrial fibrillation: a Canadian payer perspective. Thromb Haemost. 2011;105(5):908-919.

57. Freeman JV, Zhu RP, Owens DK, et al. Cost-effectiveness of dabigatran compared with warfarin for stroke prevention in atrial fibrillation. Ann Intern Med. 2011;154(1):1-11.

58. Connolly SJ, Eikelboom J, Joyner C, et al. AVERROES Steering Committee and Investigators. Apixaban in patients with atrial fibrillation. N Engl J Med. 2011;364(9):806-817.

59. ROCKET AF Study Investigators. Rivaroxaban-once daily, oral, direct factor Xa inhibition compared with vitamin $\mathrm{K}$ antagonism for prevention of stroke and Embolism Trial in Atrial Fibrillation: rationale and design of the ROCKET AF study. Am Heart J. 2010;159(3):340-347.
60. Wong PC, Crain EJ, Watson CA, Xin B. Favorable therapeutic index of the direct factor $\mathrm{Xa}$ inhibitors, apixaban and rivaroxaban, compared with the thrombin inhibitor dabigatran in rabbits. J Thromb Haemost. 2009;7(8):1313-1320.

61. Lopes RD, Alexander JH, Al-Khatib SM, et al; ARISTOTLE Investigators. Apixaban for reduction in stroke and other ThromboemboLic events in atrial fibrillation (ARISTOTLE) trial: design and rationale. Am Heart J. 2010;159(3):331-339.

62. Ruff CT, Giugliano RP, Antman EM, et al. Evaluation of the novel factor Xa inhibitor edoxaban compared with warfarin in patients with atrial fibrillation: design and rationale for the Effective aNticoaGulation with factor xA next GEneration in Atrial Fibrillation-Thrombolysis In Myocardial Infarction study 48 (ENGAGE AF-TIMI 48). Am Heart J. 2010;160(4):635-641.

63. Ufer M. Comparative efficacy and safety of the novel oral anticoagulants dabigatran, rivaroxaban and apixaban in preclinical and clinical development. Thromb Haemost. 2010;103(3):572-585.
Research Reports in Clinical Cardiology

\section{Publish your work in this journal}

Research Reports in Clinical Cardiology is an international, peerreviewed, open access journal publishing original research, reports, editorials, reviews and commentaries on all areas of cardiology in the clinic and laboratory. The manuscript management system is completely online and includes a very quick and fair peer-review system.

\section{Dovepress}

Visit http://www.dovepress.com/testimonials.php to read real quotes from published authors. 